\title{
PERFORMANCE EVALUATION OF WATER TREATMENT PLANT AT NANGLOI, NEW DELHI: A CASE STUDY
}

\author{
Absar Ahmed Khan ${ }^{1}$, Syed Khursheed Ahmad ${ }^{2}$ \\ ${ }^{I}$ M.Tech. Environmental Engineering, Al-Falah School of Engineering and Technology, Al-Falah University, \\ Faridabad, Haryana, India \\ ${ }^{2}$ Associate Professor, Civil Engineering Deptt, Al-Falah School of Engineering and Technology Al-Falah University, \\ Faridabad, Haryana, India
}

\begin{abstract}
The performance evaluation becomes mandatory to check whether water treatment plants(WTP) along with its units are capable of purifying water as per the current drinking water standards. The study aims at assessing the performance of WTP located at Nangloi in west Delhi. Performance is measured for physio-chemical parameters viz. turbidity, total solids, temperature, total solids, suspended solids, pH, Dissolved Oxygen, Residual Chlorine and water loss. Grab samples were collected from 6Nos locations viz. inlet chamber, out let of four clarifiers and after filtration on hourly basis and were analysed as per current standards of drinking water as per IS:10500. Since this WTP draws water from a surface water source, most of the water quality parameters are found to be within limits of the drinking water except turbidity and microbial contents. It was observed that turbidity of final water has always been within the desirable limit of 1NTU. Microbial contamination is taken care of as the chlorine levels are maintained as $1.5 \mathrm{ppm}$ in the final water. The water loss during treatment is found to be 0.36\% only.The results of the study shows that the parameters of final water meets the standards of drinking as per IS:10500 during all times and the treated water is safe for human consumption. This study will help identify less performing units and their efficiencies so that improvements can be made to get better quality of water at minimum cost.
\end{abstract}

Keywords: Water Treatment Plant, Performance evaluation, Water Quality Parameters, Grab Sampling, Water quality Standards

\section{INTRODUCTION}

Drinking water is the most important natural resource as only less than $1 \%$ of the total water on the planet is potable and accessible. Sustained supply of safe and potable drinking water is of paramount significance in promotion of health and well being of the people.

Over the years, the standards for drinking water have been made stringent; however the process for purification remains the same. The individual units of treatment plant have been designed keeping in consideration the drinking water standards at the time of construction. It is mandatory to check whether treatment plants along with its units are capable of delivering water as per the current drinking water standards and to identify areas which need improvement in order to improve the functioning of WTP and get better results in terms of quality of water, operation costs, wastage of water etc.

The performance evaluation of a treatment plant is a process to measure the functioning efficiencies based on some established performance indicators such as degree of removal of pollutants such as turbidity, colour, suspended impurities etc. Developed countries have developed a comprehensive performance evaluation program however no such manual exists for developing countries such as India.
Operational difficulties are also identified through such evaluations and therefore, these difficulties can be overcome to achieve smooth functioning of plant. Also, Performance Evaluation programs or studies are good experimenting with innovative technologies in the water treatment systems so as to get better quality of water at minimum cost.

The instant case is the Nangloi WTP of 40MGD situated in the south west of the capital city, Delhi (28.670295, 77.049525). The plant is based on conventional technology having units pre-settlers, transmission of raw water for a distance of $20 \mathrm{Kms}$, inlet chamber, flash mixer, clariflocculators, rapid sand filters, chlorinator. The plant is supplying water to the area which is a fast growing urban area facing the problems of inadequate supply.

Ajay and Khedikar(2016) carried out a performance evaluation of WTP at Midc Hingna, Nagpur which showed that aeration increased DO by upto $50 \%$ while overall turbidity removal in clariflocculator and filtration is $77.3 \%$ and $60 \%$ respectively. Madhu and Soumyashree(2016) also conducted similar study on WTP at Davangere, Karnataka where raw water was observed to be less turbid during summer season. It was also found that disinfection was done in unequal intervals and in unequal concentrations leading to poor quality of water. In another study done by Arshad 
et.al.(2012) on WTP in Islamabad, the turbidity removal was $91 \%$ while microbial removal was $100 \%$ and the final water was safe for human consumption. After the study on Kpong WTP, Anipa and Helen(2001) observed blackening of filter media necessitating further investigations. Bhosale et.al. (2017) carried out treatability performance of Navi Mumbai WTP. In their study, Karan and Bhave(2016) laid emphasis on performance optimisation of WTP. Shoaib and Deepak(2017) while studying Motijheel WTP established that yellowish colour of raw water due to decomposition of green algae can be treated by doing aeration and prechlorination. Hossain et.al.(2017) found that Gopalganj WTP in Bangladesh was treating physical parameters to over $99 \%$, chemical parameters to $31-89 \%$ and bacteriological up to $91 \%$. They recommended for improvement in disinfection to make water bacteriologically safe. Ashish(2014) evaluated performance of WTP at
Yavatmal and revealed that turbidity of treated water occasionally exceeds desired values.

\section{METHODOLOGY}

The instant case is the Nangloi WTP of 40MGD capacity. The plant is based on conventional technology having units viz. pre-settlers, inlet chamber, pre-chlorination, alum dosing, flash mixer, clariflocculators, rapid sand filters, post-chlorination.

A methodology has been laid down to implement a performance evaluation program.

\subsection{Site Selection}

Six locations were selected for collecting samples as shown in Fig. 1 below;

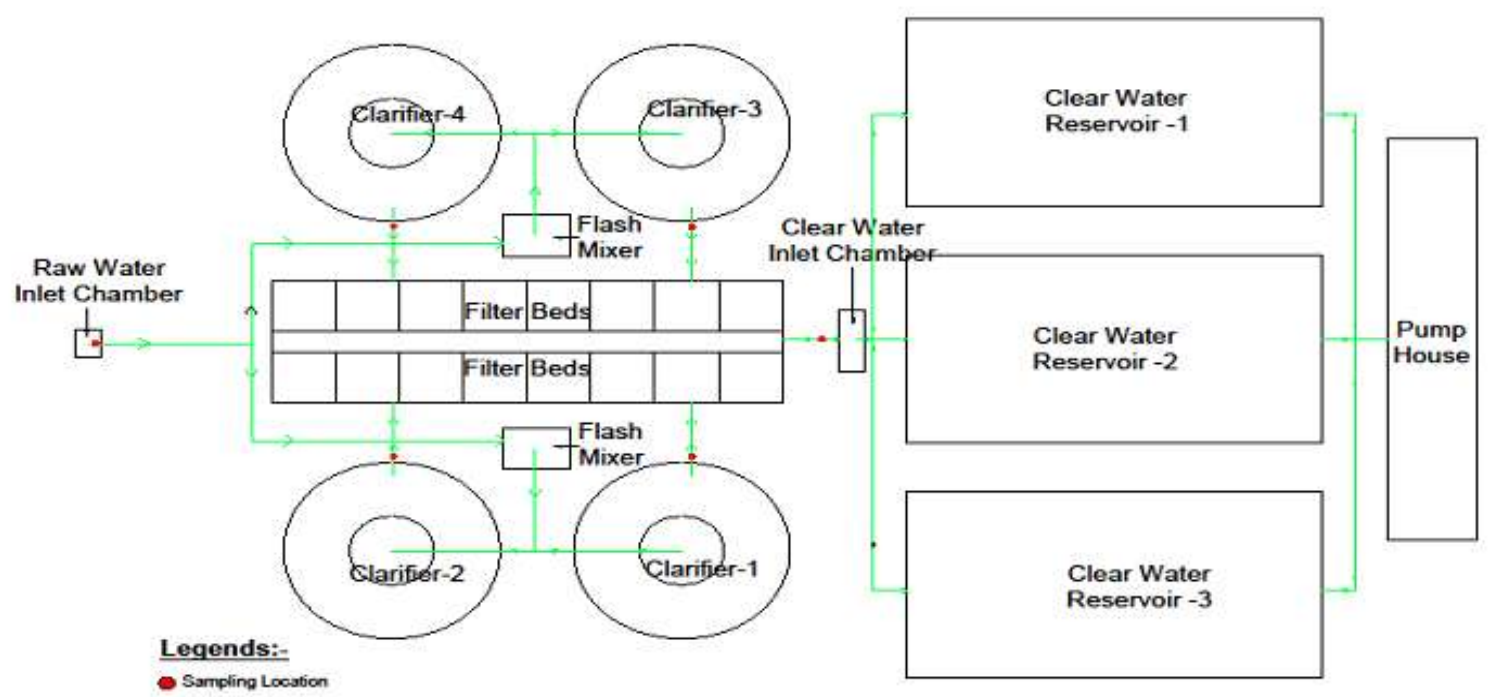

Fig 1: Layout of WTP showing sampling locations

\section{Locations;}

- Raw Water Inlet Chamber-1 No.

- Clarifiers Outlets-4 Nos.

- Filter Water Outlet-1 No.

\subsection{Sampling Procedure and Frequency}

Grab sampling was done during March and August months to get representative samples for lean and monsoon period to test performance at minimum and maximum loads. The sampling for turbidity, Res Chlorine, $\mathrm{pH}$ were done on hourly basis while for DO, TH and TDS, it was done on 4 hourly basis. Water loss readings were taken once daily to find out daily loss of water in treatment.

\subsection{Sample Analysis and Parameters Considered}

Various water analysis techniques used are as below;

\begin{tabular}{|l|l|}
\hline Parameter & Techniques \\
\hline Turbidity & Nephelometric Method \\
\hline Total Dissolved Solid & Gravimetric Techniques \\
\hline Total Solid & Analytical Method \\
\hline $\mathrm{pH}$ & Electrometric method \\
\hline Dissolve Oxygen & Winkler Method \\
\hline Residual Chlorine & $\begin{array}{l}\text { Stabilized neutral } \\
\text { Orthotoludine }\end{array}$ \\
\hline Water Loss & $\begin{array}{l}\text { Electromagnetic Flow } \\
\text { meters }\end{array}$ \\
\hline
\end{tabular}




\section{RESULTS AND DISCUSSION}

\subsection{Turbidity}

Turbidity is observed to be on lower side during March while it peaked during monsoon period. In both cases, the turbidity in the final water is found to be within the desirable limit of 1NTU. The efficiency of WTP is on higher side when turbidity in raw water is higher and vice versa.

The observed data for 3rd March 2018 to represent lean period in terms of turbidity is given below graphically in Fig.2 to Fig.8;

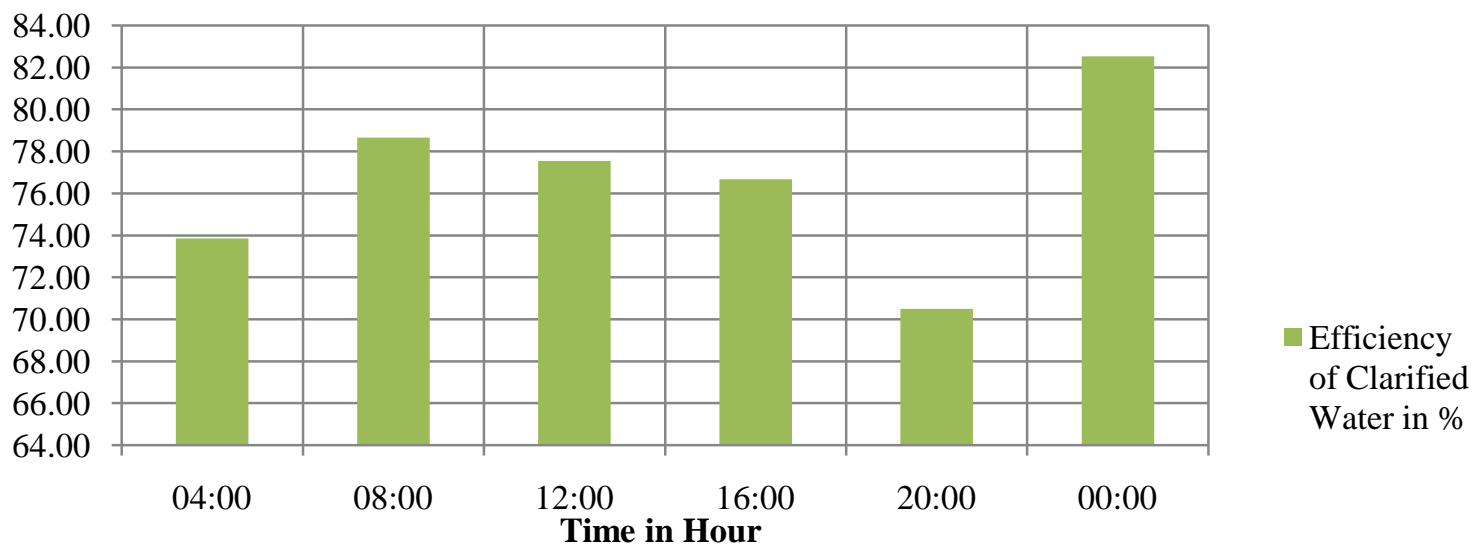

Fig-2: Four Hourly Efficiency of Clarified Water in percentage

Fig 2 shows the efficiency of clarifiers in terms of removal of turbidity and is found to be $82 \%$ at night while it was minimum at around $8 \mathrm{pm}$ on that particular day.

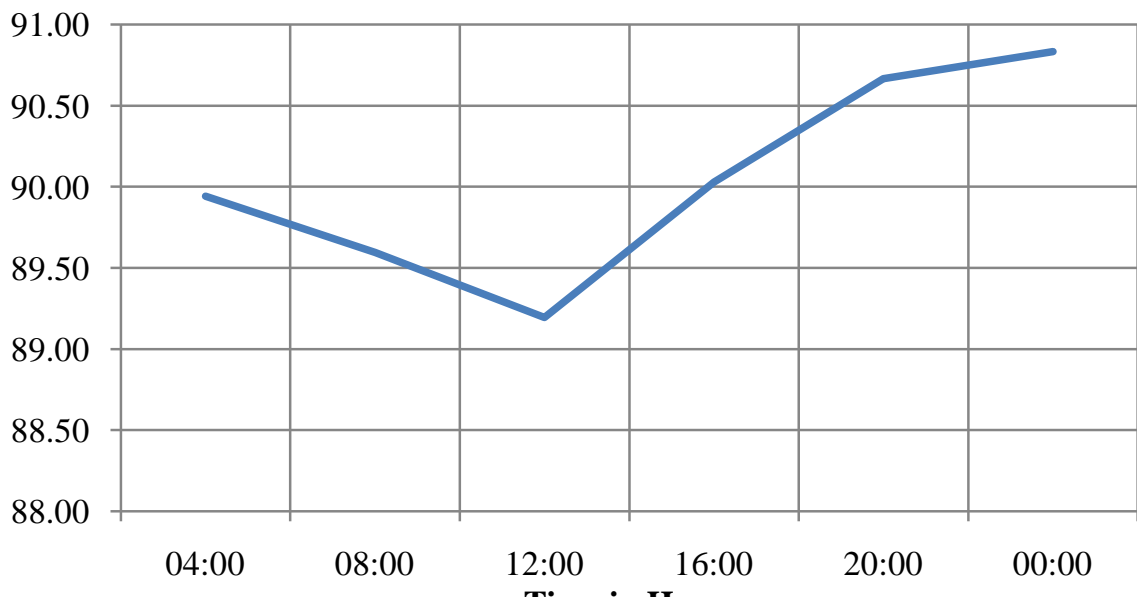

Efficiency of

Filteration in \%

Fig-3: Efficiency of Filtration in percentage

Fig 3 shows the trend of efficiency of filtration process. It peaks at night and observed to be minimum around mid day. However, the average efficiency remains around $90 \%$. 


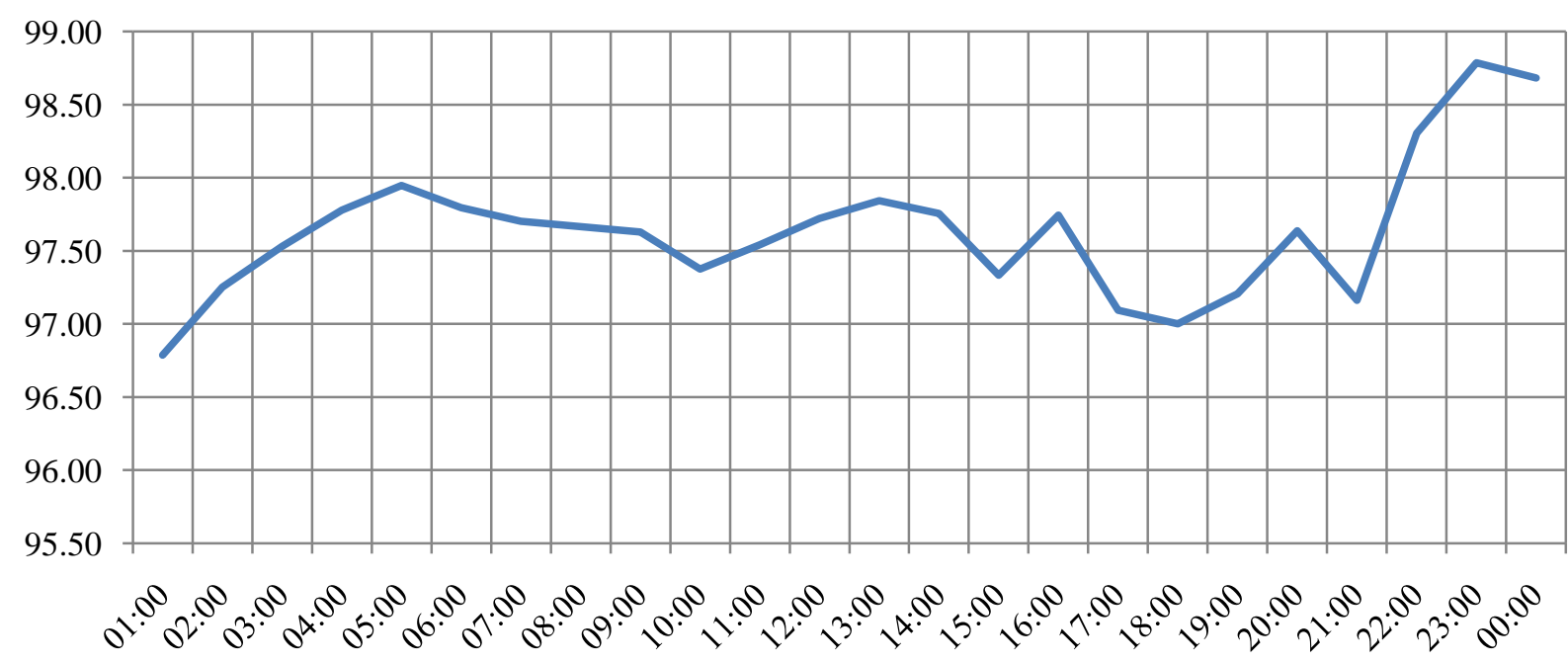

Time in Hour

Fig-4: Combined Efficiency of WTP

Similarly the combined efficiency of WTP in terms of turbidity removal almost touches $99 \%$ at night while during the day time it hovers around $97-98 \%$.

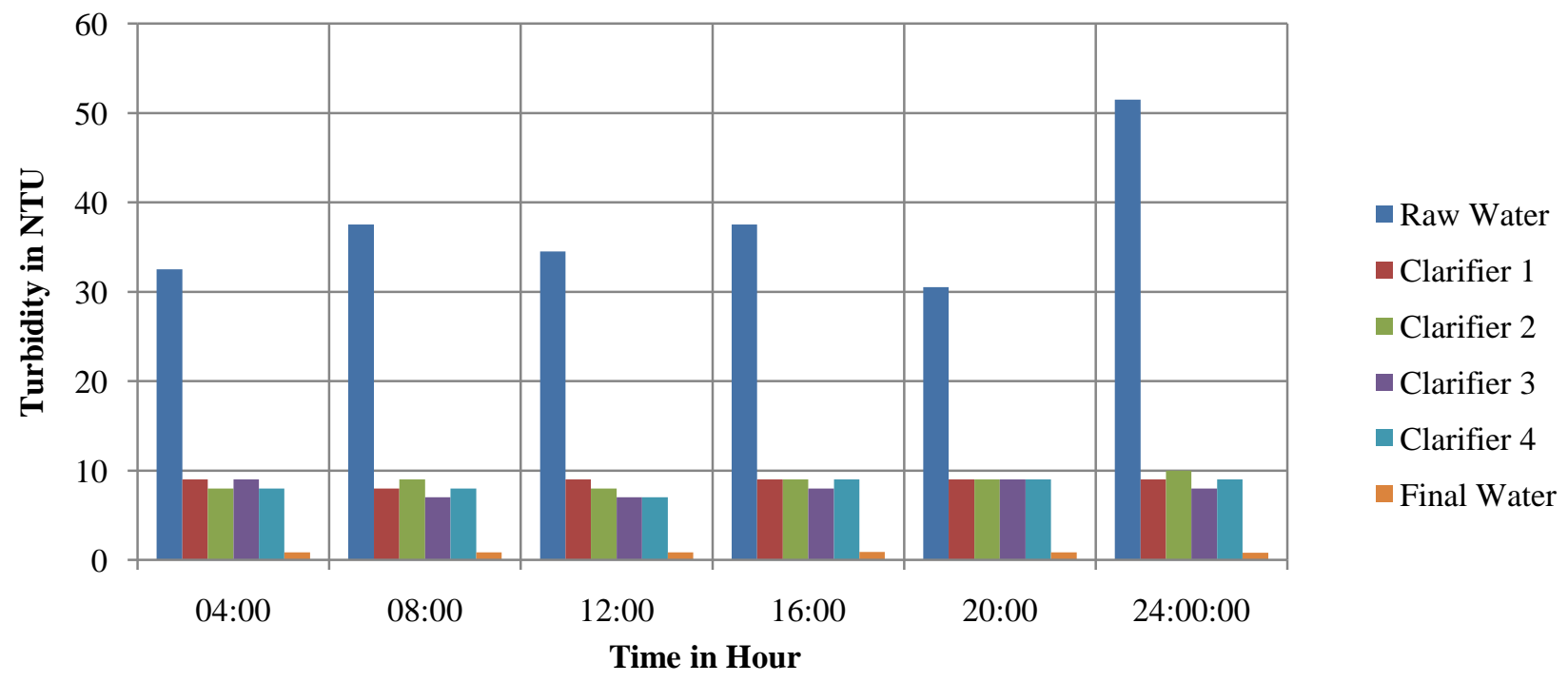

Fig-5: Turbidity at various stages 


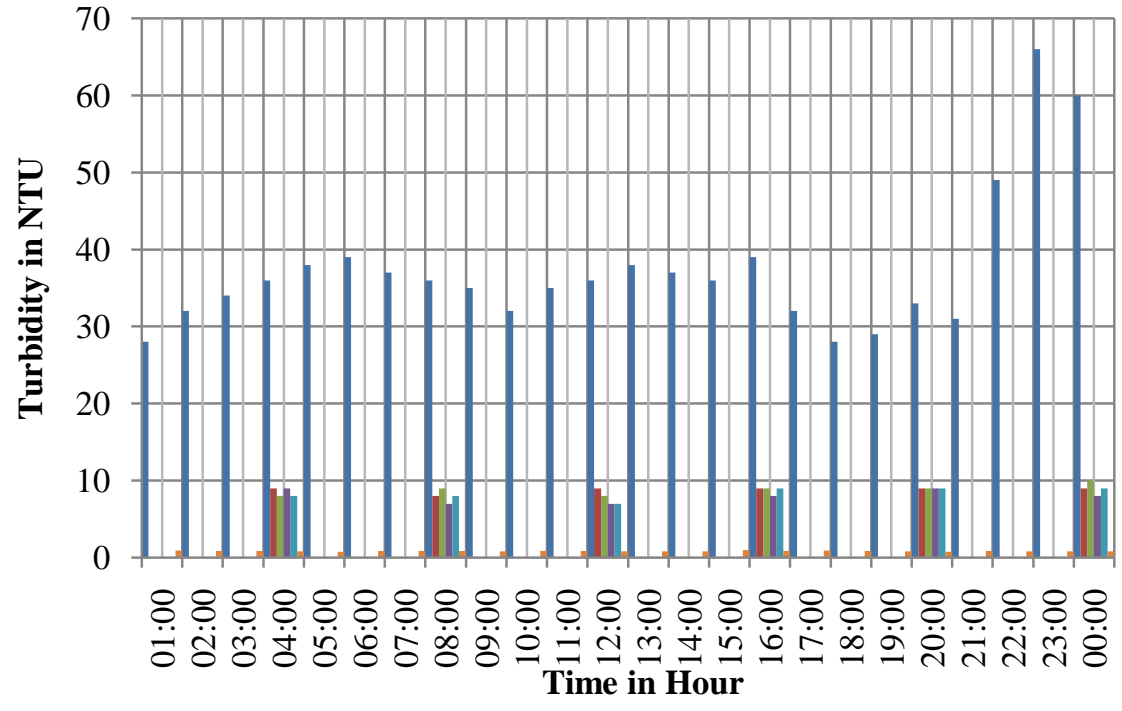

Fig-6: Levels of Turbidity in Various Effluents

\author{
- Raw Water \\ Turbidity in NTU \\ - Clarifier 1 \\ Clarifier 2 \\ Clarifier 3 \\ - Clarifier 4 \\ Final Water \\ Turbidity in NTU
}

Fig. $5 \& 6$ shows the turbidity levels of raw water, clarified water and final water. It further reveals that while the turbidity of raw water during this month of March remains between 30 to $40 \mathrm{NTU}$, it occasionally goes up to 60. Apart from this the turbidity of clarified water always remains below 10NTU. And the turbidity of final water after filtration is always under desirable limit of 1NTU. It demonstrates that the coagulation and retention time are in right proportion and adequate.

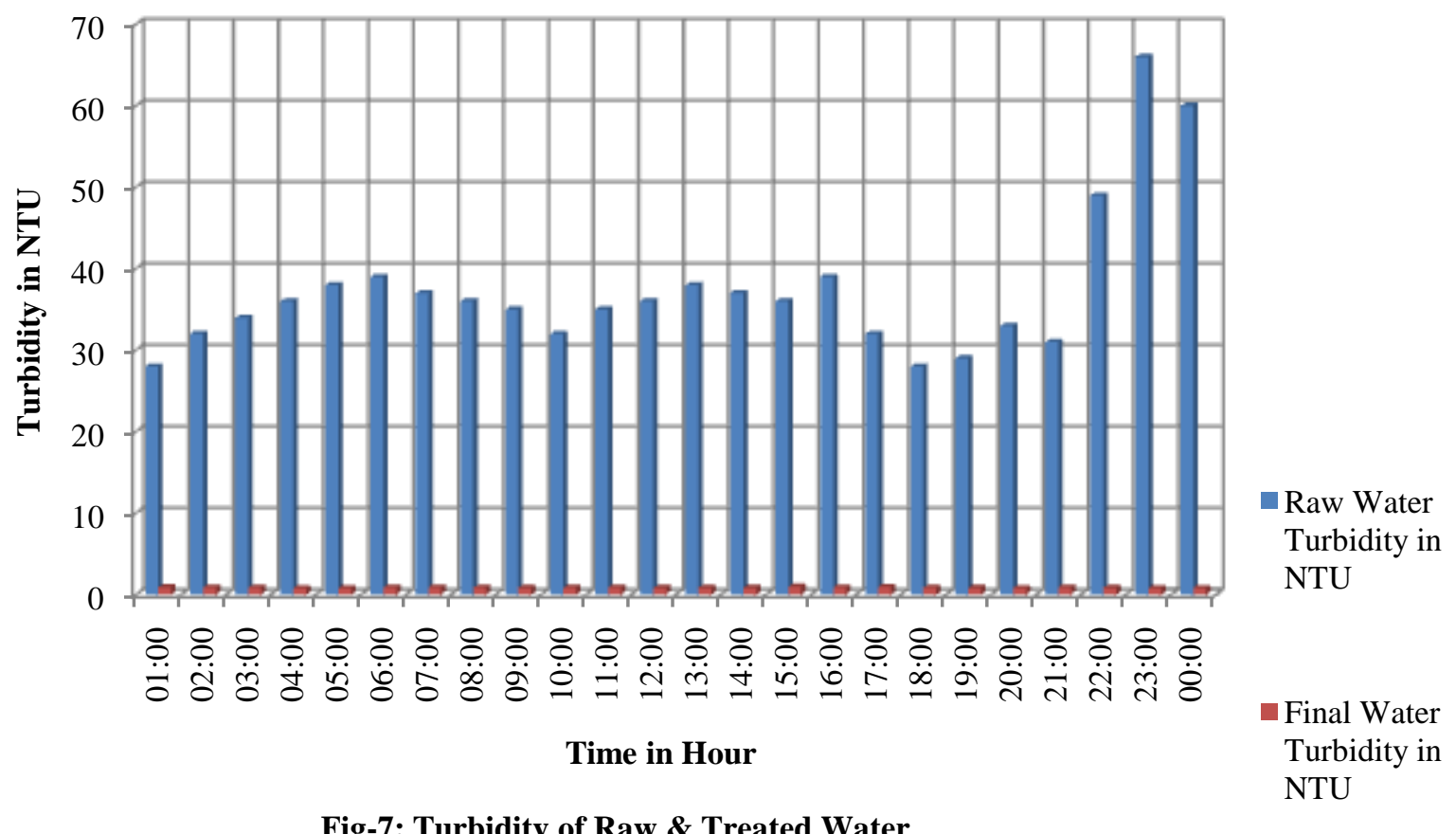

Fig 7 gives a comparative account of the turbidity levels of influent versus effluent. 


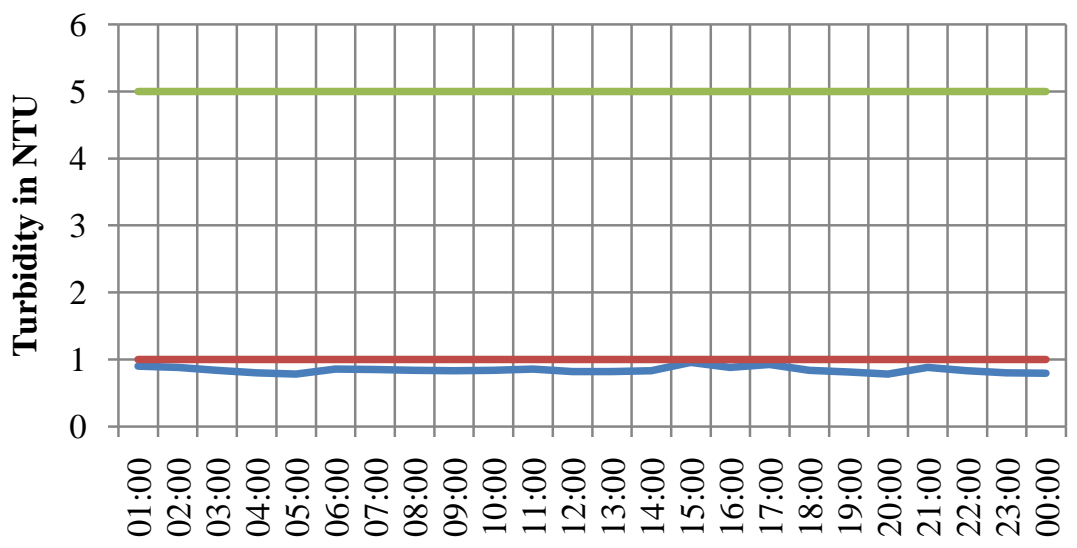

Time in Hour

Fig-8: Turbidity of Final Water

\section{Final Water \\ Turbidity in NTU \\ Standard Desirable \\ Turbidity of \\ Drinking Water \\ Standard \\ Acceptable \\ Turbidity of \\ Drinking Water}

Fig.8 gives a comparison of turbidity of final water against desirable and allowable limits of turbidity in drinking water. It is revealed that at all times the turbidity in treated water remains within the desirable limit. This demonstrates the functioning of clarifiers and filtration along with coagulant dosing has been in perfect sync.
Similarly, the results of a monsoon day i.e 24.8.2018 to represent functioning of WTP during a monsoon day when turbidity peaks, were also analyzed and shown graphically in Fig.9 to 13 as below;

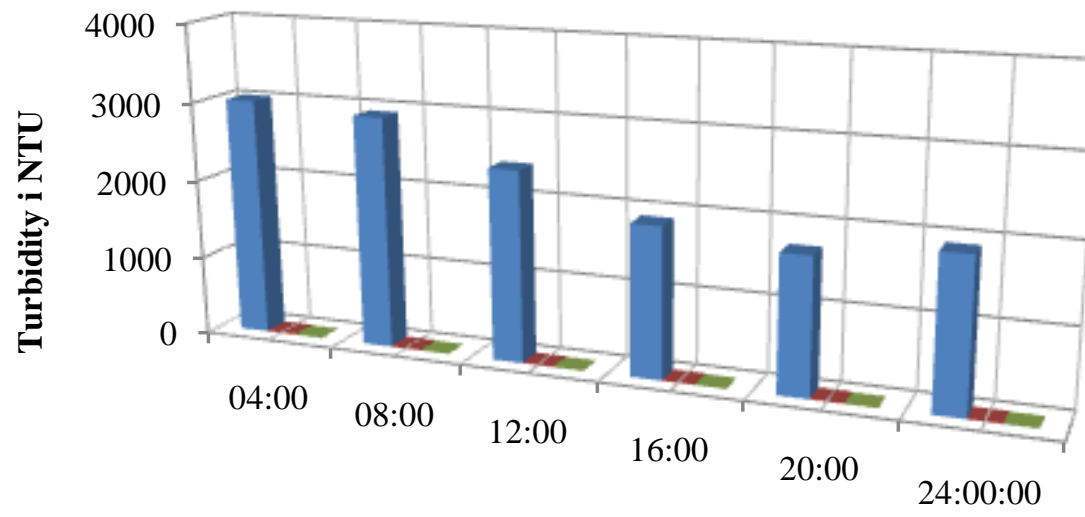

Time in Hrs
- Raw Water Turbidity

- Clarified Water Turbidity

Final Water Turbidity

Fig-9: Turbidity at Various units

Fig.9 shows the turbidity levels of raw water, clarified water and final water. It further reveals that while the turbidity of raw water during this month of August i.e. monsoon period remains between 2000 to 3000 NTU during the wee hours, it goes down to below 2000 in the day time and towards evening. Apart from this the turbidity of clarified water always remains below 10NTU. And the turbidity of final water after filtration is always under desirable limit of 1NTU.This shows that the plant is capable enough to successfully treat higher levels of turbidity during monsoon. 


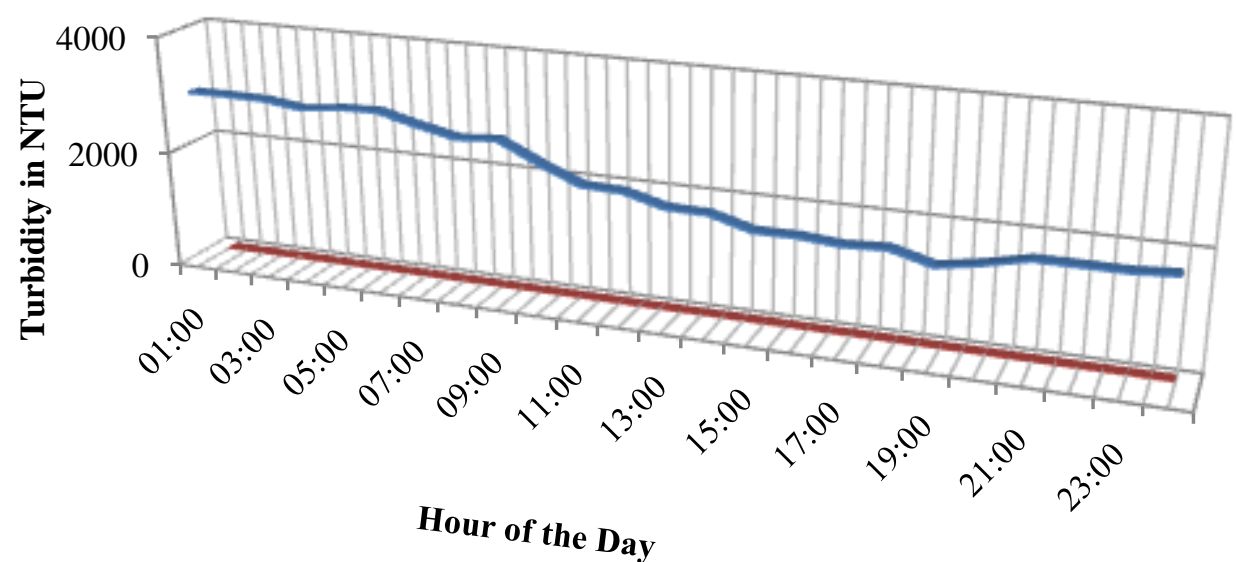

Raw Water Turbidity in NTU

- Final Water Turbidity in NTU

Fig-10: Turbidity of Raw \& Final Water

Fig.10 gives a comparative account of the turbidity levels of influent versus effluent.

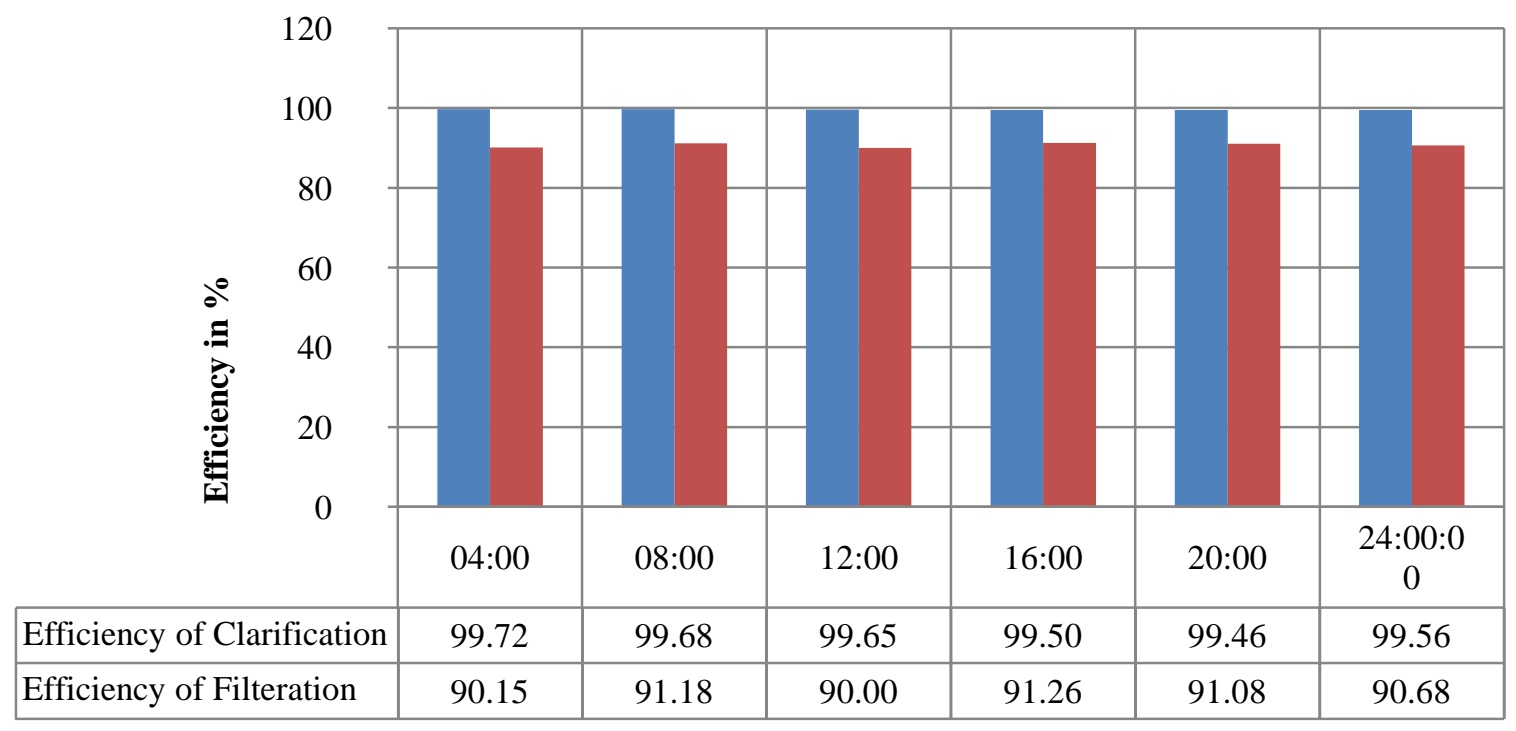

Fig-11: Efficiency of various units during monsoon

The graph in Fig.-11 shows that the efficiency of clarification touches $100 \%$ while the efficiency of filtration hovers around $90 \%$. This further demonstrates that the efficiency of plant increases with the increases in turbidity levels 


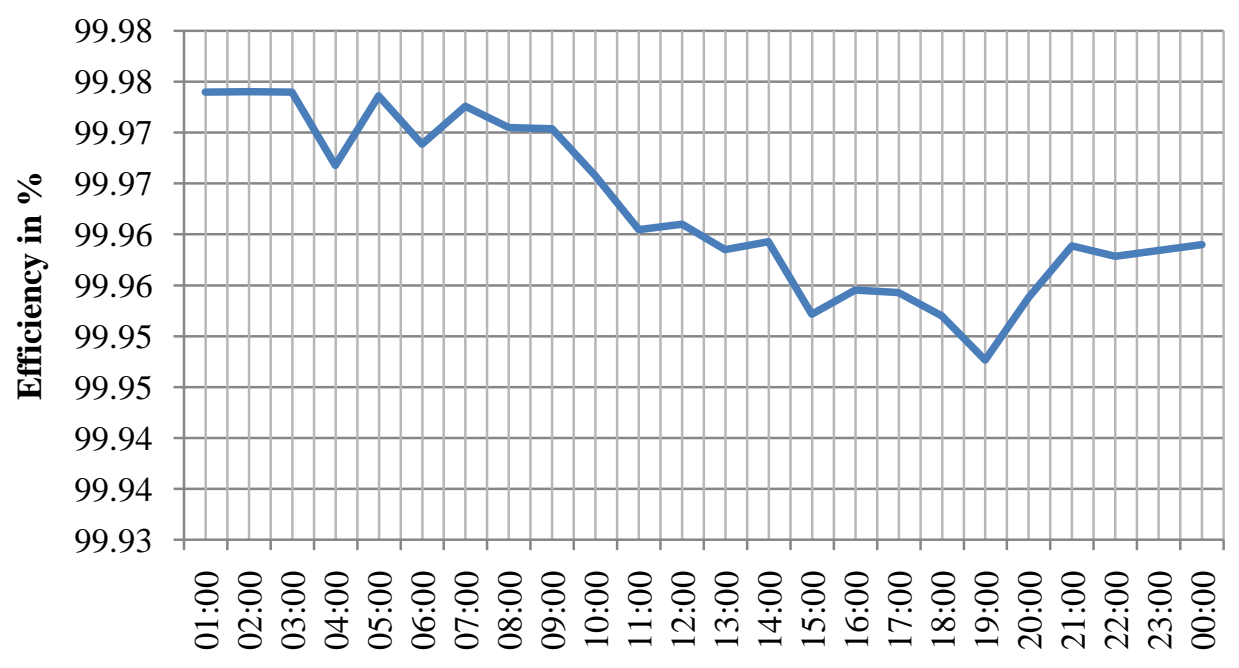

Hour of the Day

Fig-12: Efficiency of WTP dring monsoon

Fig.-12 shows the efficiency trends of the WTP during monsoon period which stays well above $99 \%$ despite of increase in load of suspended solids.

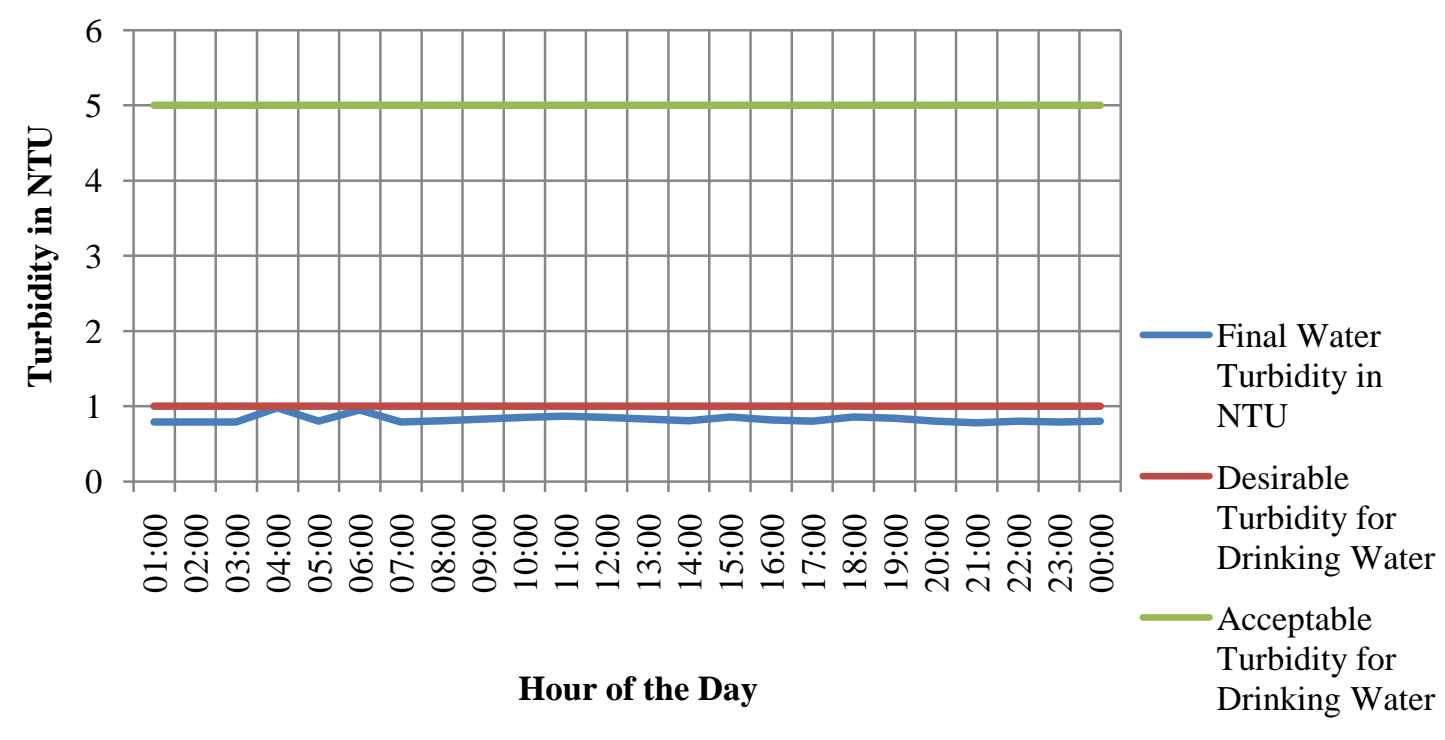

Fig-13: Turbidity of Treated Water

Fig.13 gives a comparison of turbidity of final water against desirable and allowable limits of turbidity in drinking water. It is revealed that at all times the turbidity in treated water remains within the desirable limit. This demonstrates the functioning of clarifiers and filtration along with coagulant dosing has been perfect.

\subsection{Dissolved Oxygen}

It is also observed that DO levels increases slightly as the water rushes from one unit to another and collects oxygen from air. The results are shown in Fig14 below; 


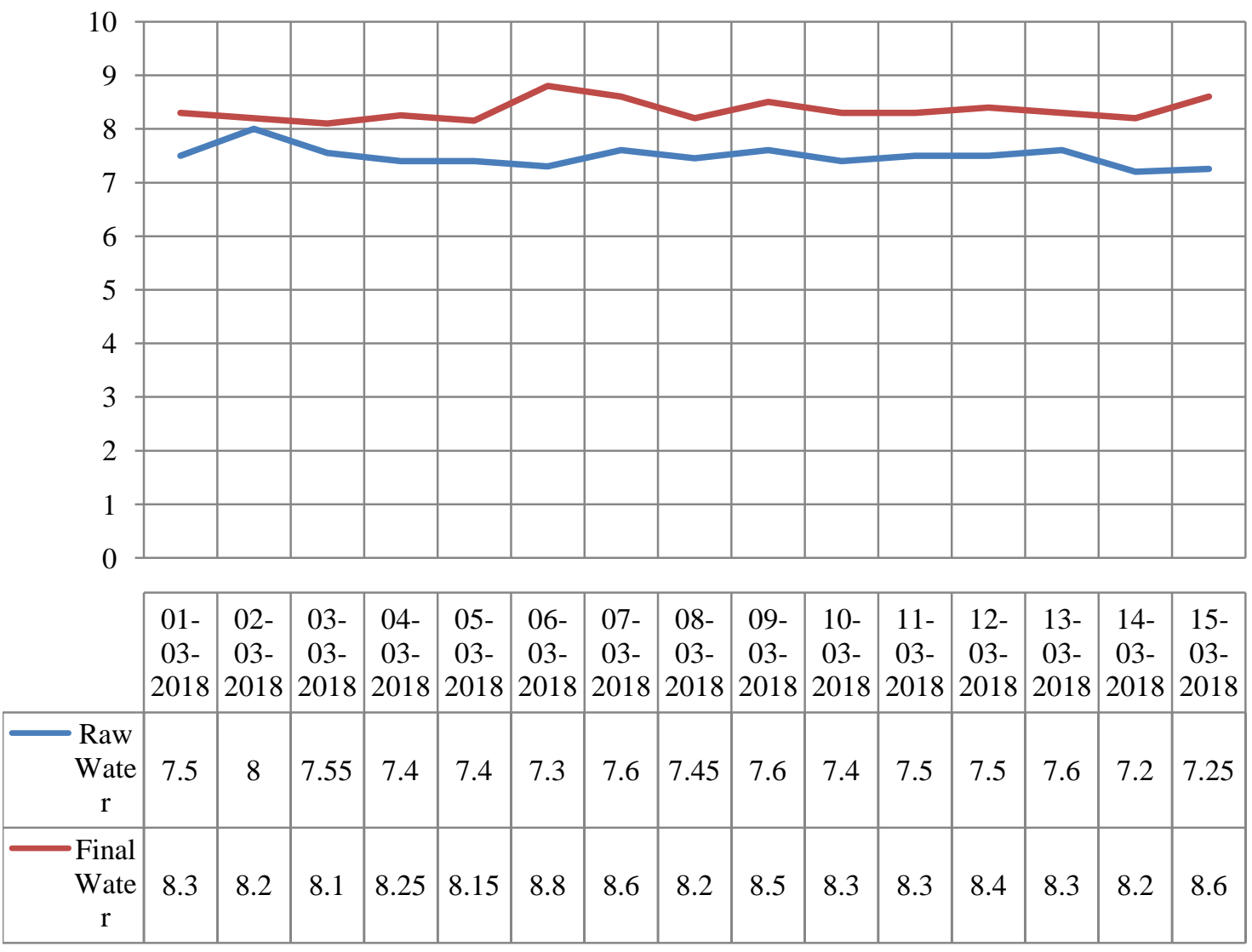

Fig-14: D.O. Levels

\subsection{TDS, pH, TH}

Other water quality parameters such as $\mathrm{pH}$, Total Hardness \& Total Hardness being measured at WTP show that all the parameters are well within the permissible limit of drinking water as per IS:10500 as show in Fig 15. However, during treatment processes the levels of TDS and TH increases slightly due to addition of chemicals for coagulation. However $\mathrm{pH}$ slightly reduces as the water gets a bit acidic due to addition of coagulants like alum and PAC.

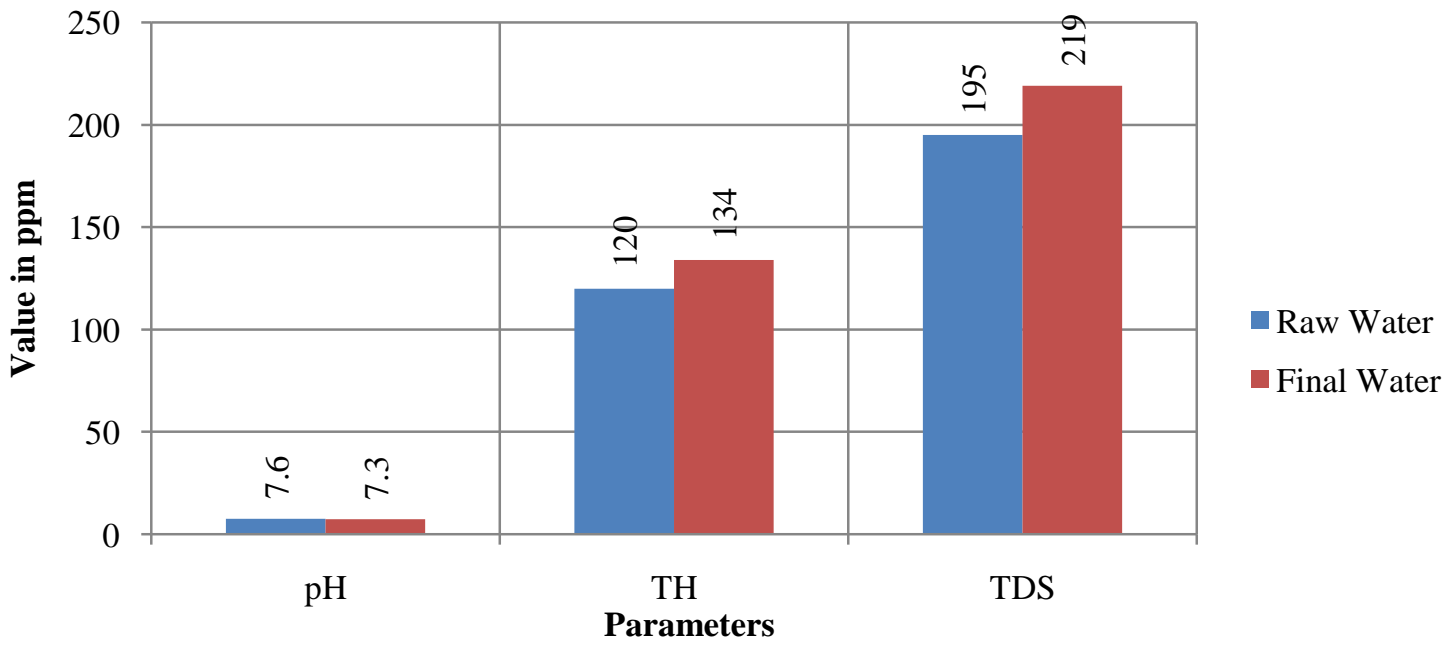

Fig-15:Other Water Quality parameters levels 


\subsection{Water Loss}

Earlier WTP did not have a recycling plant and therefore, water loss was of the tune of $3.5 \%$ while now since the addition of recycling plant the water loss has come down to below half a percent.

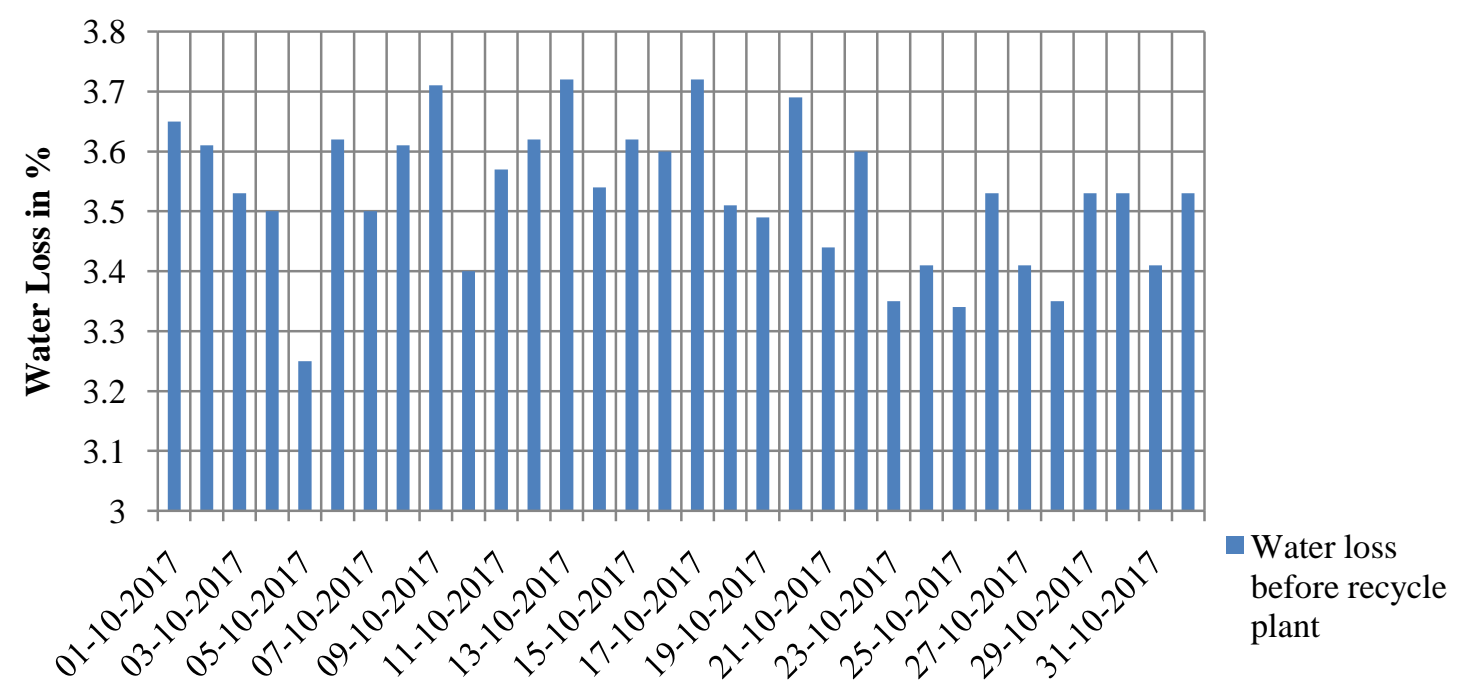

Dates

Fig-16: Water loss before recycle plant

Fig. 16 shows the water loss varying from $3.3 \%$ to $3.7 \%$ before the commissioning of recycle plant
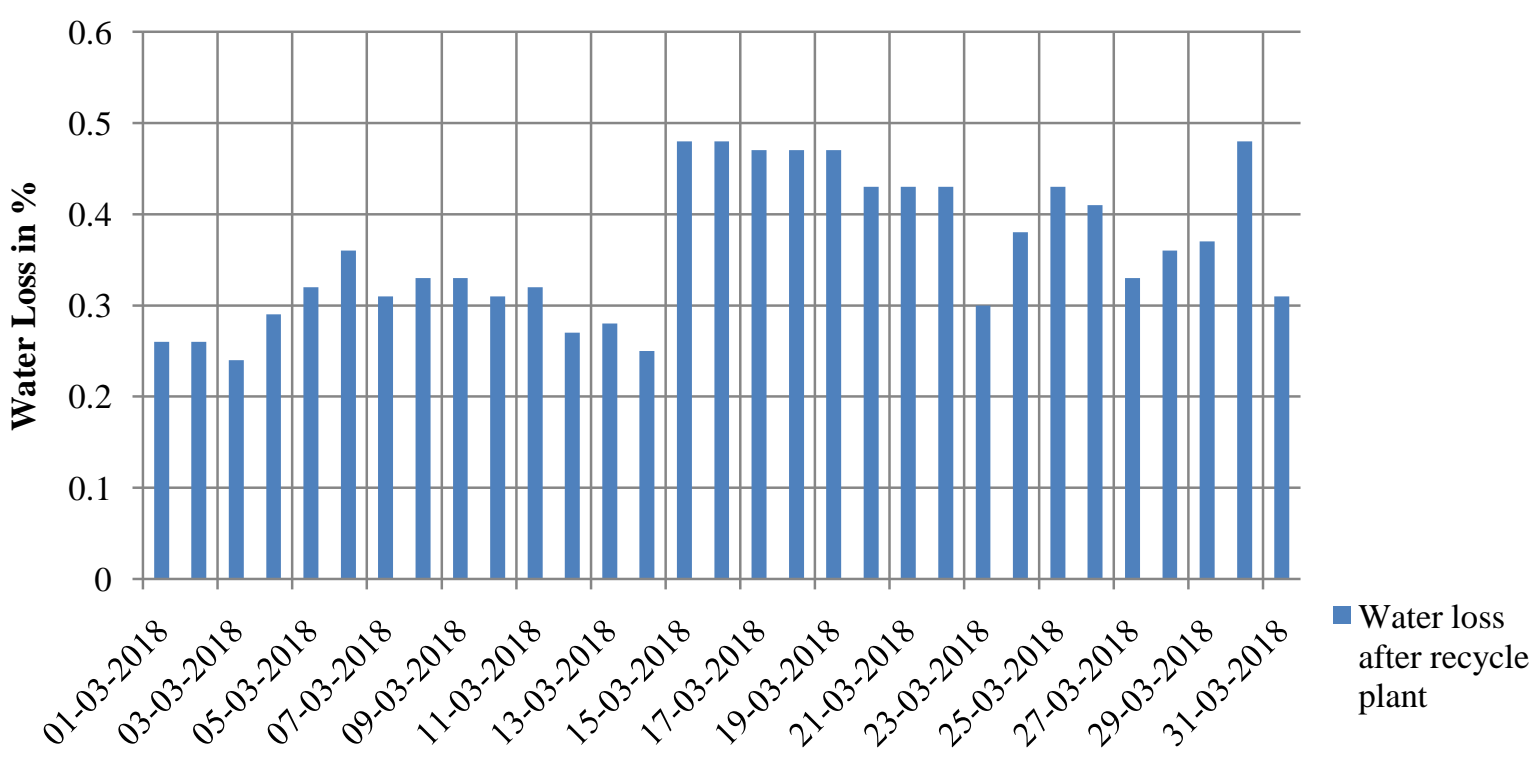

\section{Dates}

Fig-17: Water loss after recycle plant

Fig. 17 shows the water loss being well below half a percent. 


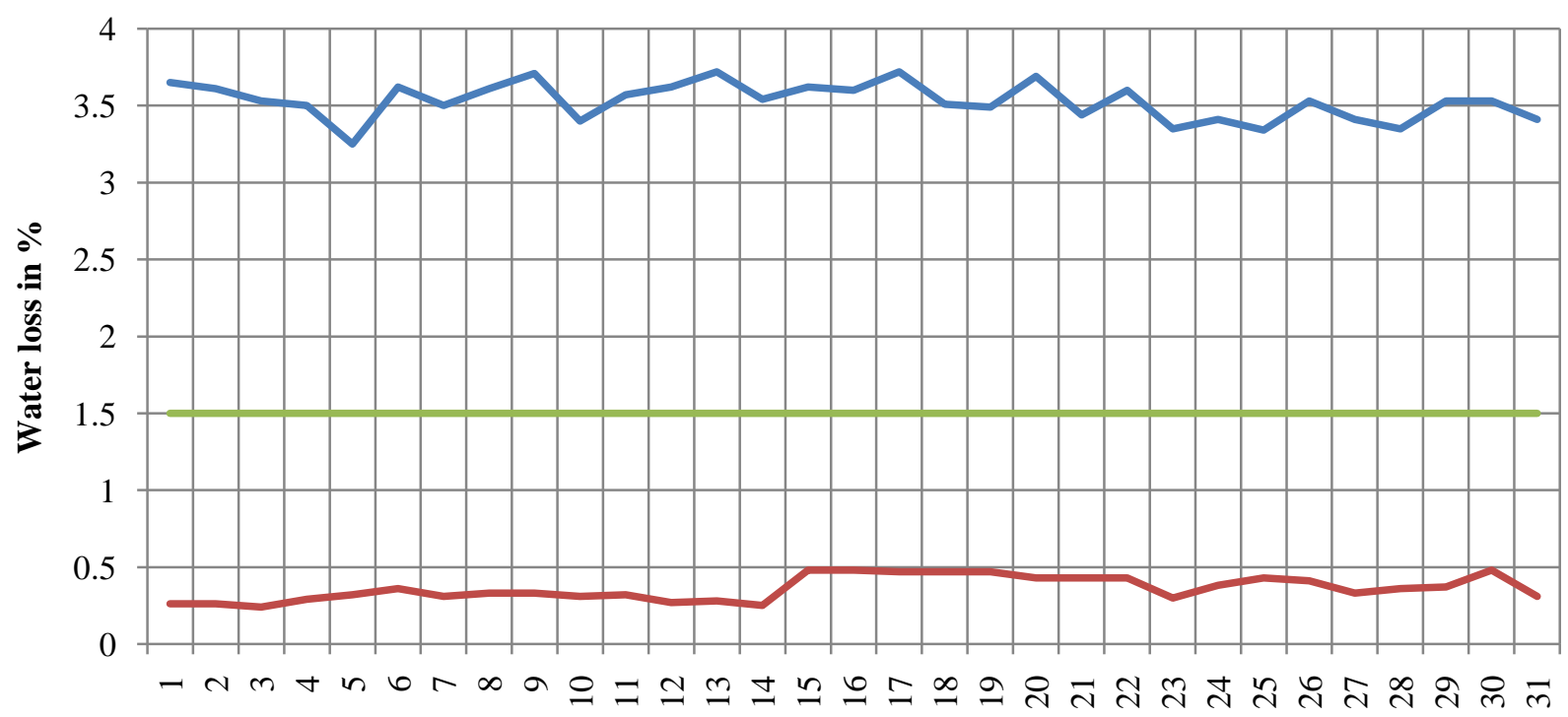

Days

Water loss before recycle plant

Water loss after recycle plant

Fig-18: Water Loss in percentage

Permissible Water Loss in Treatment

Fig.18 compares the water loss in the treatment before and after the commissioning of recycle plant with permissible value. Thus the water loss parameter is well below the permissible limit of $1.5 \%$ specified by CPHEEO.

\subsection{Residual Chlorine}

It is observed that chlorine levels are maintained as $1.50 \mathrm{ppm}$ at all times to take care of bacteriological impurities.

\section{CONCLUSION}

The results of the study show that the WTP has been successfully treating water during peak and lean loads of contaminants and final water meets the standards of drinking water as per IS:10500. Turbidity of treated water always remains within the permissible limit. Consumption of coagulant is more during monsoon due to high turbidity and vice versa. Demand of disinfectant peaked during monsoon due to higher levels of bacteriological load. Dissolved Oxygen increases as the water moves through the various unit operations. TDS and total hardness slightly increases as the water goes through various chemical processes. Water loss during treatment is well within the permissible limit set by CPHEEO. Bacteriological impurities have been taken care of by maintaining chlorine levels of $1.5 \mathrm{ppm}$ in the treated water.

\section{REFERENCES}

[1] CPHEEO Manual on Water Supply and Treatment, Third Edition published by Ministry of Urban Development, Bureau of Indian Standards; IS
10500:2012, Standard Method of American Water Works Association (AWWA), $21^{\text {st }}$ Edition(2009).

[2] Environmental Engineering by Howard S. Peavy, Donald R. Rowe, George Tchobanolous

[3] Ashish R.Mishra And Prashant A. Kadu 'Performance evaluation of WTP at yavatmal (M.S): Case Study' International Journal of Research in Advent Technology, Vol.2, No.5, May 2014

[4] Ajay S. Mahinge and Isha.P.Khedikar 'Performance Evaluation of Water Treatment Plant at Midc Hingna, Nagpur: A Case Study in India'International Journal for Scientific Research \& Development Vol 4, 2016

[5] Mohammad Shoaib khan and Prof. Deepak Rastogi, a case study 'Performance Evaluation of WTP at Motijheel, Gwalior' International Journal for Research in Applied Science \& Engineering Technology (IJRASET) Vol 52017

[6] Madhu K.M and Soumyashree S.H 'Performance Evaluation of a Water Treatment Plant at Davangere (Karnataka)' International Research Journal of Engineering and Technology 2016

[7] M. S. Hossain, M. S. Reza, M. A. Halim and Habibur Reza, a case study 'Performance Evaluation Of Drinking Water Treatment Plant In Gopalganj Town Of Bangladesh' International Conference on Civil Engineering for Sustainable Development,2016

[8] Arshad Ali, Hashim Nisar Hashmi, Naseem Baig, Shahid Iqbal and Khurram Mumtaz a case study 'Performance evaluation of the water treatment plants of Islamabad - Pakistan' ARCH. ENVIRON. SCI. (2012), 
[9] Anipa, Helen Michelle Korkor 'Performance Evaluation of Lpong WTP' KNUST Space 2001.

[10] Bhosale S M, Kulkarni A A and Pujari S S, 'Performance Evaluation of WTP at Bhokarpada Navi Mumbai' IJCSEIERD 2017.

[11] Karan M Sadhwani, PPBhave 'A review of Performance Evaluation and Optimisation of WTP' IARJSET, 2016.

[12] Manoj H Mota, Shashiraj S Chougule and Yogesh S Vatkar 'Performance Evaluation of Urban Water Treatment Plant' IJSR 2013. 